\title{
Effectiveness of flood retention basins under hydrologic uncertainty
}

\author{
Joost Pol ${ }^{1,2, a}$, Hermjan Barneveld ${ }^{1,3}$, Ralph Schielen ${ }^{2,4}$, Guus Rongen ${ }^{1,2}$ and Joost Stenfert ${ }^{1}$ \\ ${ }^{1}$ HKV Consultants, PO Box 2120, 8203 AC, Lelystad, The Netherlands \\ ${ }^{2}$ Delft University of Technology, PO Box 5048, 2600 GA, Delft, The Netherlands \\ ${ }^{3}$ Wageningen University, Droevendaalsesteeg 3, 6708 PB Wageningen, The Netherlands \\ ${ }^{4}$ Rijkswaterstaat WVL, PO Box 2232, 3500 GE, Utrecht, The Netherlands
}

\begin{abstract}
Flood retention basins are widely applied to improve flood safety. The effectiveness of such basins is more sensitive for (hydrologic) uncertainties compared to other flood protection measures. This paper shows how uncertainty can be included in the effectiveness of two major types of flood retention: with fixed sills and adjustable gates. Fixed sills divert flood waters optimally only in a small range of flood levels. If the sill is optimized for a design flood, it has limited impact on events with a different peak discharge or volume. Therefore, the flood level reduction is often overestimated using design floods. Adjustable gates operated based on flood forecasts offer the possibility to divert water under a wider range of conditions and therefore these are potentially more effective and robust, depending on the forecast uncertainty. The probabilistic analysis for fixed sills includes flood duration statistics from a stochastic weather generator. For adjustable gates, we developed a decision support algorithm for the optimal moment to open the gates based on an ensemble forecast, and quantified the expected flood reduction. A case study along the Rhine river shows that an approach without hydrologic uncertainty would overestimate the effectiveness with a factor 2 to 3 .
\end{abstract}

\section{Introduction}

Large flood retention basins have been built or are under consideration in many countries as a structural measure to reduce flood risks. Examples include the Rhine and Elbe rivers in Germany (Förster et al., 2005; Plonka \& Meuser, 2013), the Danube in Hungary (Lörinc, 2010), the Mississippi in the USA (MRC, 2011) and in Switzerland (Bühlmann \& Boes, 2014). Currently, there are only few retention basins operational in the Netherlands. Along the large rivers Meuse and Rhine none have adjustable gates. However, potential new locations along the Meuse and Rhine rivers are being studied. Furthermore, several smaller dike ring areas along the upper reaches of the Meuse have been appointed for flood retention (Deltaprogramma Rivieren, 2014). These studies fit in a trend of increased attention for spatial measures for flood risk management in the Netherlands 'Room for the River' (Klijn et al., 2004). In this paper, we apply our analysis to a large proposed retention basin in the upstream part of the Rhine river, located near the village of Lobith at the DutchGerman border (Fig 1). Due to its location, it has the advantage that it reduces flood discharges along all Rhine branches in the Netherlands.

\subsection{Retention basins and flood risk reduction}

Although retention basins can enhance ecological values and spatial quality, their main objective is to reduce flood risk, in particular flood hazard, by storing large volumes of flood waters around the peak of the flood (peak shaving). However, it has also been recognized that the risk reduction of these solutions becomes much smaller when uncertainties are taken into account (Stijnen, 2007). This is related to the fact that the discharge is only effectively reduced in a narrow range of events. Flood defenses can have a large uncertainty in the water level at which they fail, e.g. due to uncertainties in geotechnical failure mechanisms. In such cases the significant contribution of 'moderate extreme' events to the flood risk is not reduced, as the retention basins start to operate at higher discharges than the critical discharge. Another complicating factor is that in the Netherlands the protection levels of downstream flood defenses vary. Then, a single retention basin cannot deliver optimal protection for all flood defenses.

\footnotetext{
a Corresponding author: pol@hkv.nl
}

DOI 10.3311/ FLOODRisk2020.12.8 


\subsection{Sources of uncertainty}

In general, there are two types of uncertainty affecting flood risk: aleatory uncertainty which is related to natural variation of river flows (Fig. 2), and epistemic uncertainty which is due to a lack of knowledge. Examples of epistemic uncertainties are bed and floodplain roughness, river bed and land elevation, dike failure behavior and damage curves. In this paper we focus on the hydrological uncertainties only.

Which uncertainties are relevant and dominant, depends on the type of operation of the retention basin. Two major types of flood retention basins studied at present are based on (1) fixed sills or (2) adjustable gates.

In case of fixed sills, the volume which is retained in the basin and drawn from the flood wave depends on the magnitude of the flood peak and flood wave shape. There exists a certain optimum flood in terms of the retained volume. Regarding flood peak level: if it is too low it does not exceed the sill level, if it is too high the basin is full before the actual flood peak arrives. Similarly, the basin capacity may also be exceeded too early when the flood duration is relatively long. Therefore, the effectiveness for a given design discharge or return period depends also on the natural variability in flood duration (Pol et al, 2015).

In case of adjustable gates, the effect of this natural variability is less important because theoretically the gates can be managed to optimize the retained volume with any flood. However, as in this case decisions are needed based on real time flood forecasts, forecast uncertainty becomes important.

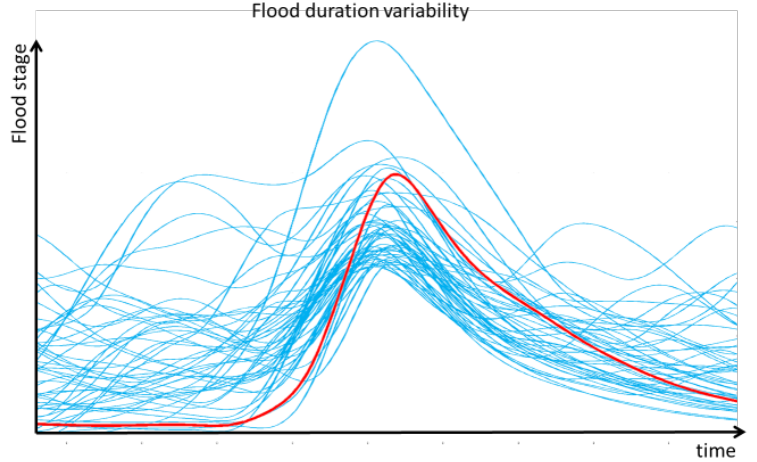

Figure 2. Illustration of the variability in flood magnitude and duration (blue curves). Based on the GRADE (Hegnauer et al., 2014) synthetic discharge dataset of the Meuse.

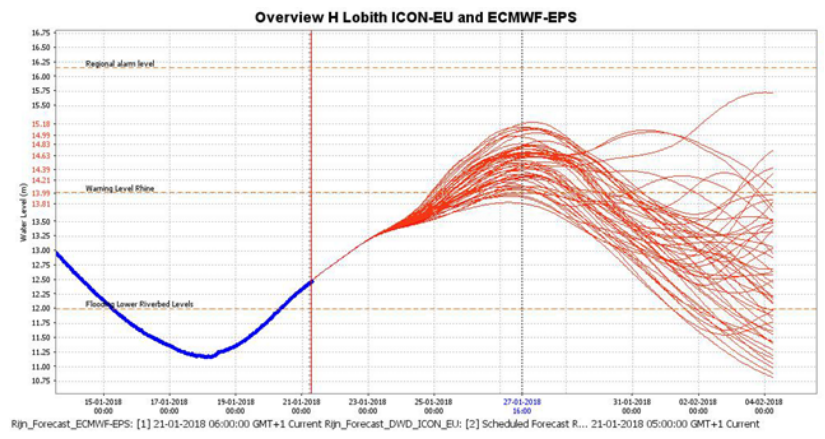

Figure 3. Example of ensemble water level forecast at Lobith (Rijkswaterstaat, 2018). Blue is historical data, red lines are ensemble members.

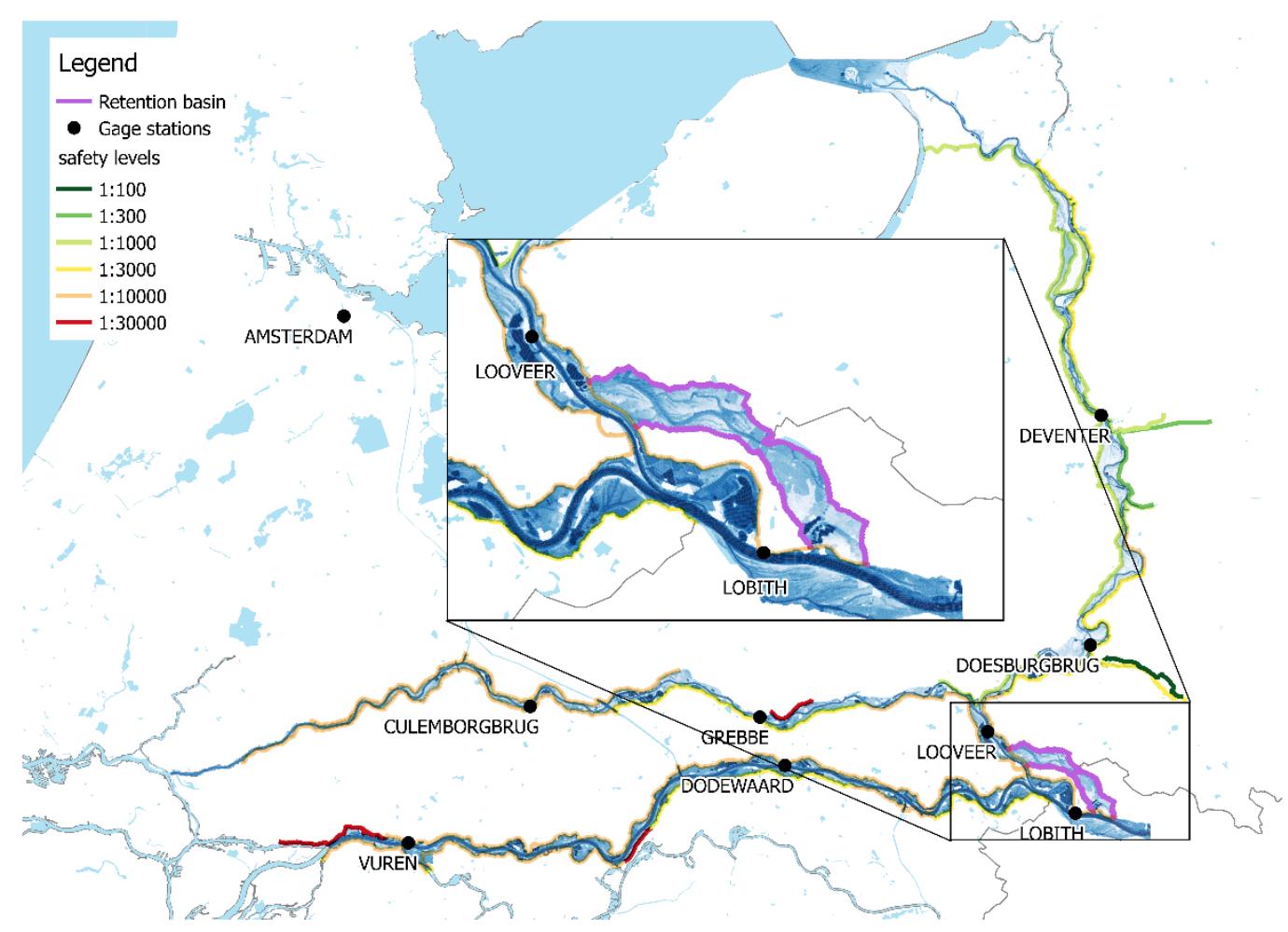

Figure 1. Location of the studied retention basin along the Rhine river near the Dutch-German border. 


\subsection{Approaches to determine effectiveness}

Effectiveness of a flood risk reduction measure can be defined in terms of water level or discharge reduction at a specified exceedance frequency, reduction in flooding probability or risk reduction. The most suitable definition depends on the type of decision problem and the desired level of detail. In this paper, we define effectiveness of retention in terms of water level or discharge reduction just downstream of the inlet structure.

A simple and common method to determine the effectiveness is to compute a reduction in water level or discharge along a river for a chosen design flood event, which is composed of a peak discharge corresponding to a given return period and an averaged flood wave shape. As this approach excludes the effect of events lower or higher than the design level, it is not suitable for the design of retention basins. This approach can be refined by using a range of discharges with corresponding return periods but still with average shape; this is the current practice in the Netherlands. Alternatively, one can use several historical floods scaled to a design peak discharge (e.g., Lammersen et al, 2002). This approach helps to identify how important the shape is, but is rather a sensitivity analysis than a method to quantify the uncertainty.

All approaches mentioned above do not quantify the uncertainty in flood duration. Therefore, in this study we developed an approach based on generated synthetic flood waves agreeing with the statistics of flood peaks and flood wave shape. The way these synthetic floods are employed to quantify effectiveness, depends on the application (natural variability or forecasting uncertainty). This is elaborated in the next section.

\section{Method of quantifying effectiveness}

The two types of flood retention basins considered, are based on (1) fixed sills or (2) adjustable gates. As described above, the relevant types of uncertainties differ for fixed sills or adjustable gates. Consequently, both require different methods for quantification of the effectiveness under uncertainty. For fixed sills, this focusses on uncertainty in hydrograph shape (natural variability); for adjustable gates on uncertainty in the forecast (epistemic).

\subsection{Fixed sills - hydrograph uncertainty}

Pol et al. (2015) describe two methods to include hydrograph variability in water level frequency calculations: an explicit method using parametric probability distributions of peak discharge and hydrograph shape, and an implicit sampling-based method. For this case, we have a sufficiently large dataset of 50,000 years of synthetic river discharges from the GRADE project (Leander et al., 2005; Hegnauer et al., 2014) to use a sampling-based approach. Moreover, the GRADE data shows a dependence between flood magnitude and duration for extreme floods, which would complicate the

a Corresponding author: pol@hkv.nl

DOI 10.3311/ FLOODRisk2020.12.8 explicit method. Therefore, here we use the implicit method, which is summarized as:

1. Select a suitable variable to quantify the hydrograph shape;

2. Select a representative subset of hydrographs;

3. Hydrodynamic simulation of this subset of events with and without the retention basin;

4. For each flood event, estimate the local water level with and without retention based on interpolation of the subset in the synthetic discharge dataset;

5. Derive the water level frequency curve from these estimated water levels.

These five steps are elaborated below.

[1] The predictive value of several shape variables on flood water levels was tested by simulating all 9667 flood events (annual maxima with peak discharge at Lobith $\left.Q_{p}>8,000\right)$ in a fast $1 \mathrm{D}$ hydrodynamic Sobek model without a retention basin, and subsequently calculating the correlation between each variable and the local peak water levels. The considered shape variables (see Fig. 4) are the flood duration at $0.85 Q_{p}\left(D_{0.85}\right)$ and at $11,000 \mathrm{~m}^{3} / \mathrm{s}\left(D_{11000}\right)$, the volume above $0.85 Q_{p}\left(V_{0.85}\right)$ and above $11,000 \mathrm{~m}^{3} / \mathrm{s}$ $\left(V_{11000}\right)$, and the peak curvature $C_{2}$ (see Eq. 2). This resulted in the selection of peak discharge $Q_{p}$ and peak curvature $C_{2}$ as predictive variables, which was also found for the Meuse river (Pol et al., 2015):

$$
\begin{gathered}
Q_{p}=\max (Q) \\
C_{2}=-\frac{Q\left(t_{p}-2\right)+Q\left(t_{p}+2\right)-2 Q_{p}}{Q_{p} d t^{2}}
\end{gathered}
$$

Where $d t=2 * 24 * 3600 \mathrm{~s}$ (two days before and after the peak).

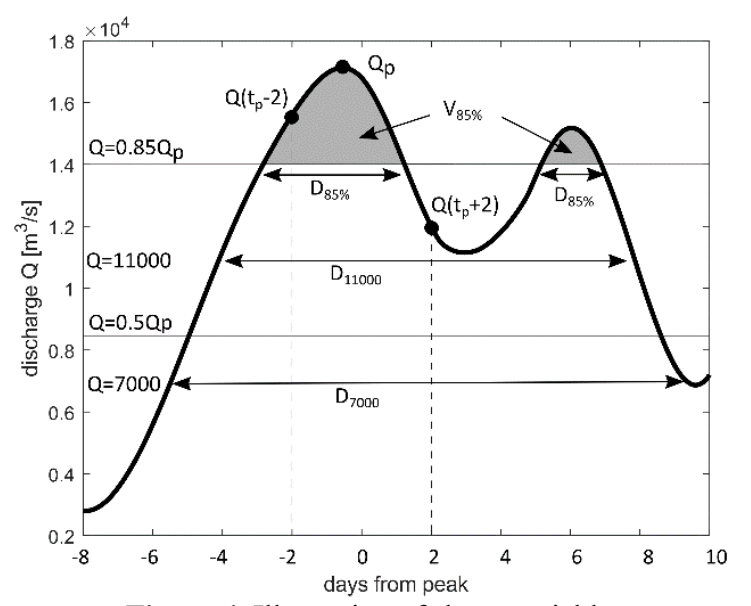

Figure 4. Illustration of shape variables.

[2] We selected a representative subset of 25 extreme events covering the range of $Q_{p}$ and $C_{2}$ found in the GRADE dataset, as shown in Fig 5 and 6.

[3] The subset was simulated using a detailed 2D hydrodynamic WAQUA model of the Rhine branches (Rijkswaterstaat, 2012; CSO, 2013). This results in the response of the peak water level $h_{\text {max }}$ at a specified location $x$ as function of the shape variables:

$$
h_{\max }=f\left(Q_{p}, C_{2}, x\right)
$$


In simulations with retention basin, the basin was included with a sill width of $600 \mathrm{~m}$ and a sill level of 16.90 $\mathrm{m}+\mathrm{NAP}$ which is the optimized level for a $\mathrm{Q}_{\mathrm{p}}=14,000 \mathrm{~m}^{3} / \mathrm{s}$ flood wave with average duration. Fig 7 shows some of the optimization steps. Note that $\mathrm{Q}_{p}=14,000 \mathrm{~m}^{3} / \mathrm{s}$ corresponds to a return period of about 600 years, which is below the design discharge/frequency of most downstream reaches; this discharge level was chosen to have enough events in the GRADE dataset which exceed the sill level to allow for a sampling-based method to demonstrate the approach. Fig 8 shows an example for location Vuren along the Waal branch.

[4] The peak water level at a specified location $x$, for each sample in the entire set of 9667 events, is estimated by linear interpolation of the WAQUA subset given in Eq 3. In this way an extensive database for impact of retention is generated using a small subset of more detailed 2D simulations. [5] Subsequently, we perform a frequency analysis on this subset to obtain return periods of $h_{\max }$. The return period $T$ (inverse of the exceedance frequency) of the water level at location $x$ is given by:

$$
T\left(h_{\max , x}\right) \approx \frac{1}{P\left(H_{\max , x}>h_{\max , x}\right)}=\frac{N_{\text {years }}}{N_{>h_{\max , x}}}
$$

With $N_{\text {years }}=50,000$ is the length of the GRADE dataset and $N_{>\operatorname{hmax}, x}$ the number of annual maximum flood events that exceed $h_{\max }$ at location $x$. The approximation is valid for return periods larger than approximately 10 years.

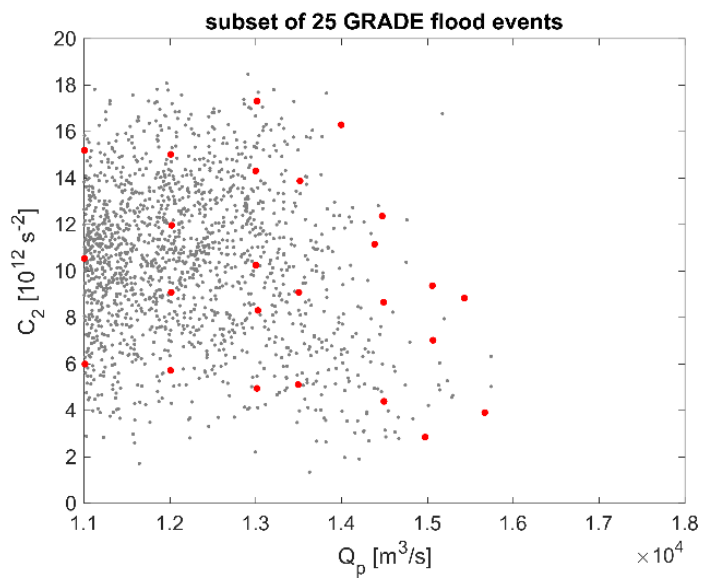

Figure 5. Distribution of subset (red dots) over all events $\mathrm{Q}>11,000 \mathrm{~m}^{3} / \mathrm{s}$.

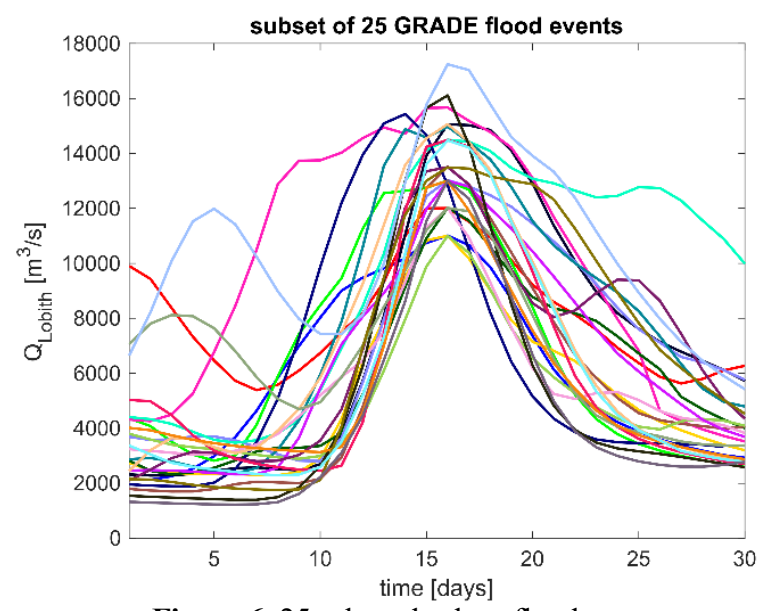

Figure 6. 25 selected subset flood events.

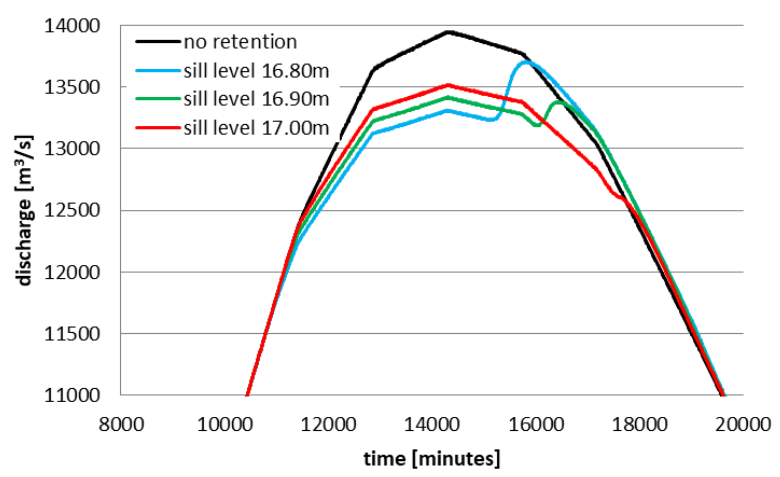

Figure 7. Optimization of sill level for $\mathrm{Q}_{\mathrm{p}}=14,000 \mathrm{~m}^{3} / \mathrm{s}$.

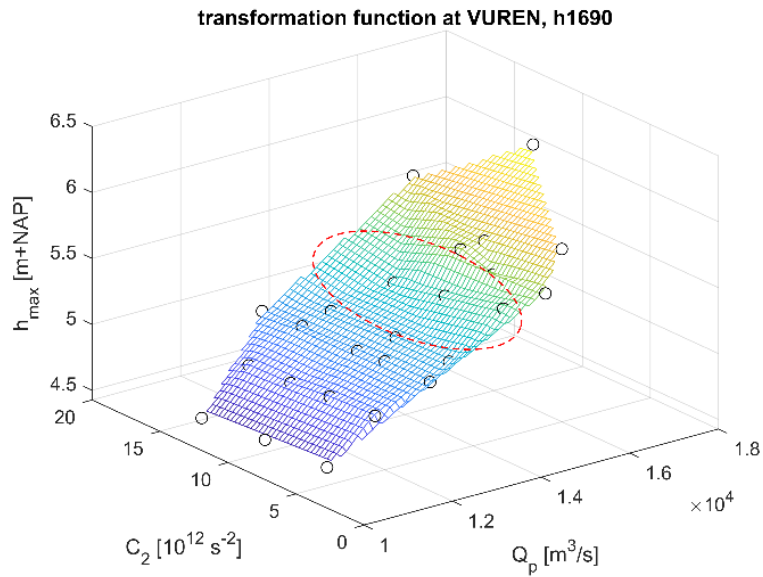

Figure 8. Example of response function with retention. The dip around $\mathrm{Q}_{\mathrm{p}}=14,000$ indicated by the dashed line is the effect of the retention basin.

\subsection{Adjustable gates - forecasting uncertainty}

Adjustable gates can be operated during a flood event based on a fixed scheme, for example by opening the retention basin if the water level at a certain location exceeds a pre-set threshold. In such cases, uncertainties have a similar effect as for basins with a fixed sill. However, in case of adjustable gates that are operated based on real-time forecasts, the quality of the forecast becomes most important instead of the natural variability in flood waves. If the forecast would be perfect, the optimal target level could be chosen correctly for any flood wave, giving a high effectiveness. This provides the theoretical maximum effect of a retention area. In the Netherlands, the forecasts are issued as ensembles, based on different weather predictions.

The method to include forecasting uncertainty in the calculations of the effectiveness is summarized as:

1. Determine the retention basin / storage volume.

2. For each time step during a flood event, use the current ensemble forecast and apply this algorithm:

a. Estimate the peak discharge reduction $d Q$ for a range of target levels for the discharge and for all ensemble members

b. Choose the target level with the maximum expected value of $d Q$. 
c. If the target level is not reached in the current time step, make a new calculation in the next time step.

d. If the target discharge level is expected to be reached in the next 24 hours, open the gate and employ the basin, i.e. divert all surplus water (discharge exceeding target level) to the retention basin. Once opened, the target level is not updated anymore.

e. If the capacity is reached, close the gate.

3. Outcomes of this procedure are for each event: the actual upstream and downstream peak discharges, the chosen target level and the optimal target level in hindsight.

The capacity of the retention basin is estimated at 80 million $\mathrm{m}^{3}$ and the analysis assumes it is independent of river discharge and not limited by the inflow structure. We have verified this assumption with 2D (WAQUA) simulations for 12 floods with varying peak discharge and hydrograph shape, and the error between assumed and simulated volume is less than $1 \%$.

Because an extensive dataset with ensemble forecasts of the Rhine at Lobith at the Dutch border was not yet available, we generated synthetic ensembles to demonstrate the method. These ensembles have a variation that is based on a limited number of available forecasts of the Rhine. Forecasts contain both meteorological uncertainty and hydrological model uncertainty. The meteorological uncertainty is estimated by fitting a linear function on the ensemble predictions of the floods of 2011 (Patzke, 2011) and 2018 (Rijkswaterstaat, 2018). Its standard deviation reads:

$$
\sigma_{Q, m e t}=0.0059 Q(t)+4.60(t-\tau)-151
$$

With $\mathrm{Q}(\mathrm{t})$ the actual discharge at time $\mathrm{t}$ in the future, $\tau$ the current time and $(t-\tau)$ the lead time. Lead time dominates this uncertainty, and the influence of discharge is relatively small. The hydrological model uncertainty is based on results of an ensemble model for the Rhine by Verkade et al. (2017). Assuming a Gaussian distribution, the standard deviation is estimated as:

$$
\sigma_{Q, h y d}=230+0.1 Q
$$

The total standard deviation, assuming independence between de Gaussians, is:

$$
\sigma_{Q}=\sqrt{\sigma_{Q, m e t}^{2}+\sigma_{Q, h y d}^{2}}
$$

We assume that the prediction is unbiased, so the mean deviation is 0 . The total uncertainty $\sigma_{\mathrm{Q}}$ was applied to 225 synthetic flood events: 25 GRADE hydrographs (Fig 6) which were all scaled to 9 peak discharges between 12,000 and $18,000 \mathrm{~m}^{3} / \mathrm{s}$. The scaling is a multiplication of the discharge so that the peak discharge equals the desired peak value. The example in figure 9 shows the increasing uncertainty with time and discharge.
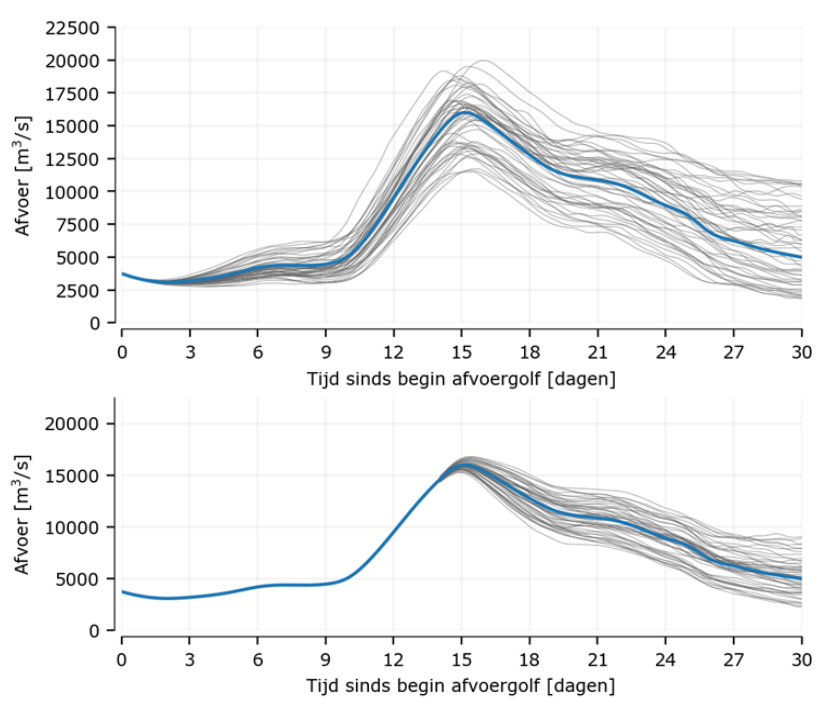

Figure 9. Examples of synthetic ensembles for different lead times.

The algorithm determines the optimal target level $Q_{d}$ in each time step $\tau$ ( 24 hours), based on the ensemble forecast at that moment and the volume of the retention basin. When the actual discharge exceeds the optimal level, the target level is kept constant (simulating flooding of the basin). The peak discharge reduction $\Delta \mathrm{Q}$ expected at each time step is the weighted average peak discharge reduction of all $n$ ensemble members, as a function of target level $Q_{\mathrm{d}}$ :

$$
\begin{aligned}
& \Delta Q\left(Q_{d}, \tau\right) \\
& =\sum_{i=1}^{n}\left[\max _{\tau<t<\infty}\left(Q_{i}(t)\right)-\max _{\tau<t<\infty}\left(q_{i}\left(t, Q_{d}\right)\right)\right] P_{i}
\end{aligned}
$$

Where $Q_{i}$ is the upstream discharge in ensemble member $i, q_{i}$ the corresponding downstream discharge with deployment of the retention basin at target level $Q_{d}$, and $P_{i}$ is the probability of ensemble member $i$ (here uniformly distributed as $1 / n)$. The optimal target level at time $\tau$ is:

$$
Q_{d}(\tau)=\underset{Q d}{\operatorname{argmax}} \Delta Q(\tau)
$$

Figure 10 shows an example of the development of the optimal target level over time, as the ensembles are updated over time. As the actual discharge approaches the peak, the optimal target level stabilizes due to reduced uncertainty about the exact discharge around the flood peak.

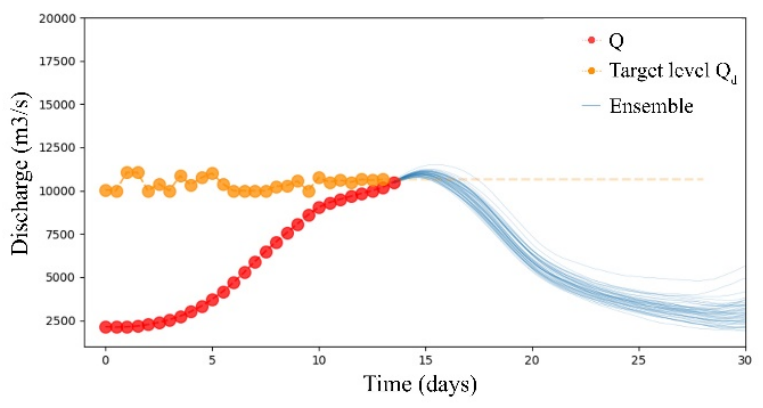

Figure 10. Development of the actual discharge and optimal target level over time in case of forecast uncertainty. 


\section{Results}

\subsection{Fixed sills}

Fig 11 and 12 demonstrate the results for the Waal river branch and location Vuren (see Fig 1) in the downstream part of the Waal, for scenarios with and without (fixed sill) retention and with average and variable shape. The water levels without retention are very similar for the standard method with average shape and the proposed probabilistic method with variable shapes. This may be expected, as the Waal river is heavily normalized and the lack of peak attenuation due to floodplain storage minimizes the influence of the flood duration (Gerretsen, 2009). However, the two methods result in a different effect of retention, especially for the specific conditions for which the sill level was optimized $\left(Q_{p}=14,000 \mathrm{~m}^{3} / \mathrm{s}\right.$, $\mathrm{T} \approx 600$ years). Including the variable shape results in $\mathrm{a}$ factor 2 lower water level reduction compared to the effect calculated using the optimization for a single design hydrograph. This factor 2 appears to be rather constant over the different locations, see also Table 1. For lower and higher return periods, the difference in retention effect between methods decreases. This means that using a range of discharges with average duration is already a major improvement compared to using a single design flood, but that it still overestimates the effectiveness for discharges around the $\mathrm{Q}_{\mathrm{p}}$ used for optimization.

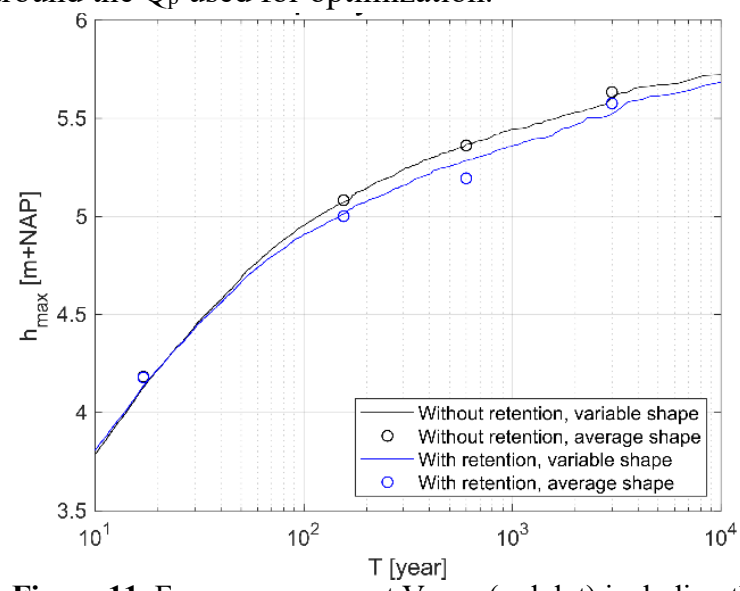

Figure 11. Frequency curve at Vuren (red dot) including the effect of the retention basin (blue dot).

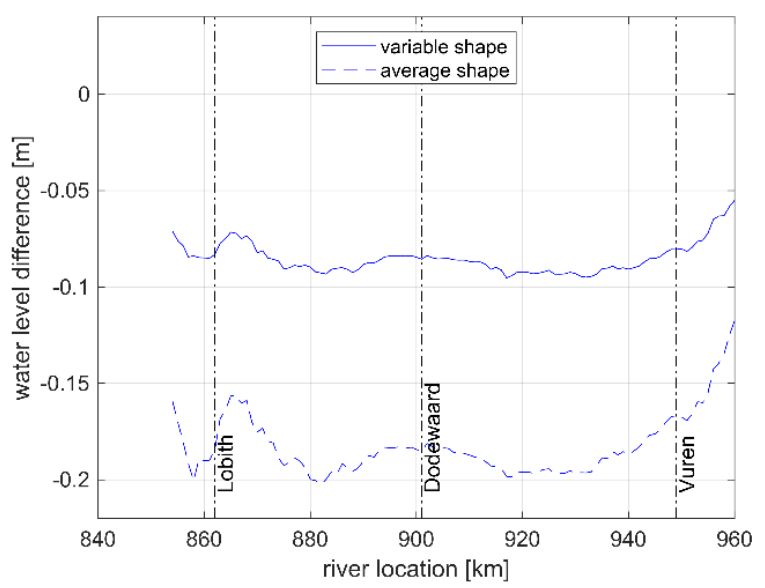

Figure 12. Water level effect on the Waal branch due to the retention basin, for $\mathrm{T}=600$ years.

\begin{tabular}{|l|l|c|c|c|c}
\hline & & \multicolumn{2}{|c|}{$\mathrm{T}=600 \mathrm{y}$} & \multicolumn{2}{c}{$\mathrm{T}=3,000 \mathrm{y}$} \\
\hline Location & Branch & average & $\begin{array}{c}\text { variabl } \\
\mathrm{e}\end{array}$ & average & $\begin{array}{c}\text { variabl } \\
\mathrm{e}\end{array}$ \\
\hline Lobith & Rhine & 0.18 & 0.08 & 0.05 & 0.05 \\
\hline Vuren & Waal & 0.17 & 0.08 & 0.06 & 0.08 \\
\hline Culemborg & Lek & 0.12 & 0.06 & 0.04 & 0.06 \\
\hline Deventer & IJssel & 0.09 & 0.04 & 0.05 & 0.04 \\
\hline
\end{tabular}

Table 1. Water level reduction [m] by a retention basin optimized for $\mathrm{Q}_{\mathrm{p}}=14,000 \mathrm{~m}^{3} / \mathrm{s}(\mathrm{T} \approx 600$ years $)$, for both average and variable flood wave shape.

\subsection{Adjustable gates}

Table 2 summarizes the effectiveness in terms of average peak discharge reduction $\Delta \mathrm{Q}$ per peak discharge level $Q_{p}$. In the case of deterministic 'perfect' forecasts (column $\Delta \mathrm{Q}_{\mathrm{det}}$ ), the discharge reduction is on average $622 \mathrm{~m}^{3} / \mathrm{s}$, whereas it drops to $239 \mathrm{~m}^{3} / \mathrm{s}$ when the forecast uncertainty is included (column $\Delta \mathrm{Q}$ prob). On average, the ratio $\Delta Q_{\text {prob }} / \Delta Q_{\text {det }}$ is $33 \%$, so the assumed forecast uncertainty of $\mathrm{Eq}$ 5-6 results in a factor 3 lower effectiveness compared to the most optimistic scenario of a perfect forecast.

The increasing value of the discharge reduction $\Delta \mathrm{Q}_{\text {det }}$ with discharge level $Q_{p}$ can be explained by scaling of the hydrographs (section 2.2). This scaling leads to relatively peaked floods for a higher discharge level, and therefore a larger $\Delta \mathrm{Q}$ for a given storage volume. For $\Delta \mathrm{Q}_{\text {prob }}$ this effect is counterbalanced by the increasing uncertainty with increasing discharge level (Eq 5 and 6). This leads to a relatively constant $\Delta Q_{\text {prob }}$ for a wide range of discharge levels or return periods.

\begin{tabular}{|c|c|c|c|}
\hline $\begin{array}{c}Q_{p} \\
{\left[\mathrm{~m}^{3} / \mathrm{s}\right]}\end{array}$ & $\begin{array}{c}\Delta \mathrm{Q}_{\text {det }} \\
{\left[\mathrm{m}^{3} / \mathrm{s}\right]}\end{array}$ & $\begin{array}{c}\Delta \mathrm{Q}_{\text {prob }} \\
{\left[\mathrm{m}^{3} / \mathrm{s}\right]}\end{array}$ & $\begin{array}{c}\Delta \mathrm{Q}_{\text {prob }} / \Delta \mathrm{Q}_{\text {det }} \\
{[\%]}\end{array}$ \\
\hline 12,000 & 572 & 201 & 30 \\
\hline 13,000 & 594 & 257 & 37 \\
\hline 14,000 & 608 & 229 & 34 \\
\hline 15,000 & 622 & 275 & 38 \\
\hline 16,000 & 638 & 231 & 31 \\
\hline 17,000 & 654 & 241 & 32 \\
\hline 18,000 & 664 & 242 & 31 \\
\hline average & 622 & 239 & 33 \\
\hline
\end{tabular}

Table 2. Mean peak discharge reduction using perfect and uncertain forecasts.

Although the value of $Q_{p}$ has little influence on $\Delta Q_{\text {prob}}$, the differences in discharge reduction between individual hydrographs are large. The effectiveness is relatively low in case of floods with a prolonged duration around te flood peak. Figure 13 illustrates the determined target levels and discharge reductions for a relatively short (Fig 13a,b) and prolonged (Fig 13c,d) flood event in the subset of 25 events. For the short flood wave, the chosen target level is close to the optimum without uncertainty, resulting in a discharge reduction of $800 \mathrm{~m} 3 / \mathrm{s}$ compared to $850 \mathrm{~m} 3 / \mathrm{s}$ without uncertainty. However, in case of the long flood wave, the chosen target level is too low. On the one hand because the discharge reduction $\Delta \mathrm{Q}$ is more sensitive for the target level $\mathrm{Q}_{\mathrm{d}}$ (black line in Fig 13d). Stated differently: the basin is effective for a narrower range of target levels. 


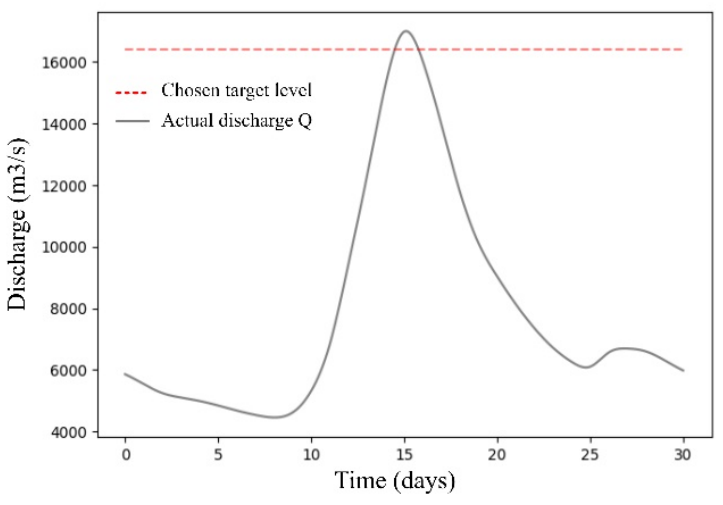

a.

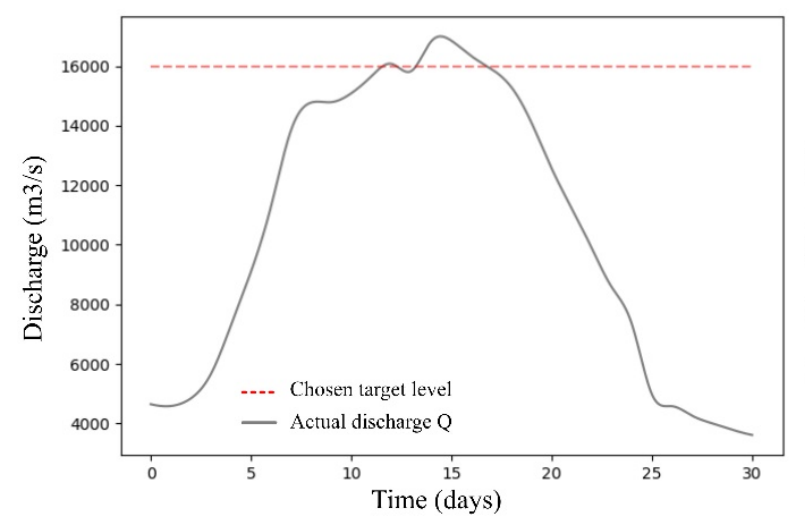

c.

Figure 13. Illustration of the result of the optimization for short and prolonged floods.

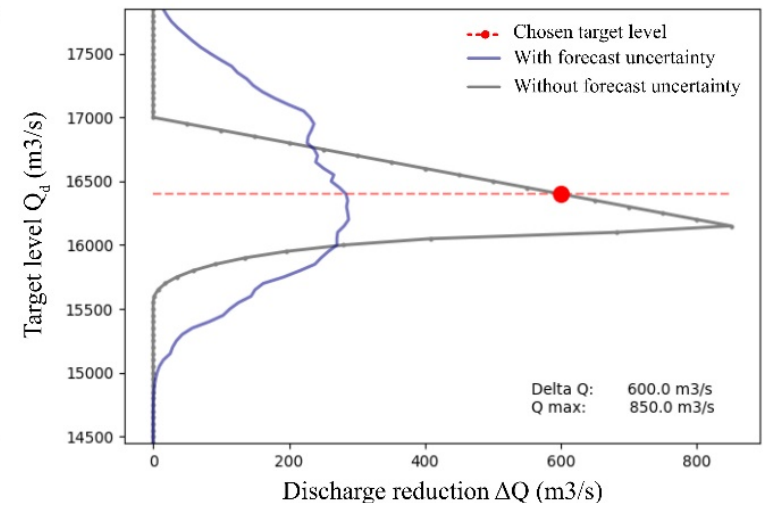

b.

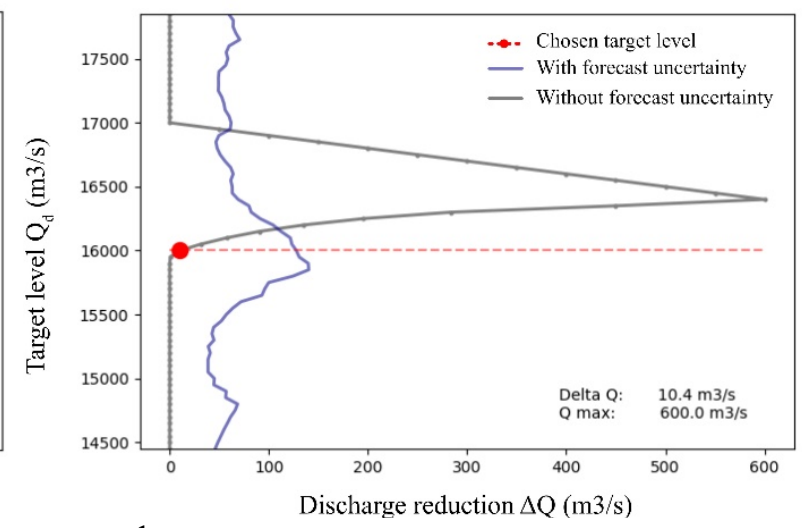

d.
Additionally, the flatter peak forces the algorithm to make a decision in an earlier stage, resulting in more uncertainty about the effect and a higher probability that the inlet is opened too early or too late .

\section{Discussion}

In this section we first point out a few limitations of the described method, and then we describe some proposed extensions of the method.

A first limitation of the fixed sills method is that it is based on a sampling approach, which puts a limitation on the return period that can be investigated. In this case, there was a 50,000-year dataset of synthetic discharges available, which allows to analyze return periods up to about 10,000 years. A possible adaptation of the method in case of smaller datasets or larger desired return periods, is to parametrize the statistical distributions of peak discharge, hydrograph shape and its correlation. Then the parametrized distributions can be combined with the response function to obtain the exceedance frequencies of the local water levels. Secondly, the analysis only considers hydrologic uncertainties. Other uncertainties, such as flood plain roughness, may further reduce the effects.

The first limitation of the adjustable gates method is that the effectiveness is estimated based on the optimal strategy determined using an algorithm. In practice, the gates may be opened based on other considerations, which reduces the effectiveness. For the presented case study, another limitation is that the forecast uncertainty in the ensembles was estimated from a very limited number of historical ensembles. The magnitude of the forecast uncertainty strongly determines the effectiveness of retention with adjustable gates. For further assessments and decision-making, it is essential to have more accurate information on the forecast uncertainty of the forecasting system in use.

A limitation of both approaches is that effectiveness is only determined in terms of water level reduction or discharge reduction, and not in terms of flood risk. That is acceptable for optimization problems, but may be insufficient in case of decisions between different alternative measures for which a risk-based approach is more suitable.

The presented method can be extended to a risk-based approach in both the planning or decision-making phase of a new retention basin and in the operational phase of a basin with adjustable gates. In the planning phase, this can be done by including all relevant uncertainties (e.g., dike fragility curves, floodplain roughness) and information on potential flood damage and casualties in the analysis of the effectiveness of a retention basin. In the operational phase, the expected effects for each target level can be defined in terms of total costs (flooding damage in the retention basin against expected flood risk reduction downstream), see for example Dale et al. (2014). This helps to identify in which events it is beneficial to use the retention basin, which is also helpful in communicating the decisions to other stakeholders. 


\section{Conclusions}

Large flood retention basins can be potentially very effective in water level reduction over large reaches downstream of the basin. Basins are flooded by flow over a sill with a fixed crest level, by the opening of gates at a fixed flood level, or by the adaptive opening of gates based on forecasts. Basins flooded at a fixed level are most common, not the least because this is much easier te operate and communicate. The inlet structures of these fixed sill basins are usually optimized to yield a maximum discharge reduction for a given design flood event. However, in practice it is difficult to identify a single design event for which the measure yields an optimal system risk reduction. First, because there required safety levels vary along the downstream river. Second, because geotechnical failure mechanisms form a significant contribution to the flooding probability. These mechanisms generally have large uncertainties, and hence relatively large failure probability at low-magnitude events. Furthermore, compared to other measures like river widening or dike heightening, the effectiveness of retention is relatively sensitive to small changes in conditions such as the local water level, so retention is less robust. For example, when there is a small increase in the design discharge, the sill level should be adjusted accordingly. Robustness of retention increases when it works in a range of uncertain conditions, for example a cascade of basins with different flooding frequencies (Klijn et al., 2004) or by gates which are controlled based on flood forecasts.

We analysed retention basin effectiveness including hydrological uncertainties, for the scenarios of fixed sills and adjustable gates in a case study along the Rhine river. Natural variability in flood duration, an important uncertainty source for fixed sills, reduces the effectiveness of the fixed sill retention basin by approximately a factor two compared to using a single design event with average flood duration. Of course, the impact of forecast uncertainty on retention with adjustable gates strongly depends on the variability of the ensemble forecast as function of discharge and lead time. With our assumptions regarding this uncertainty, we find a factor three lower effectiveness compared to perfect forecasts. Hence both types of retention are significantly less effective due to hydrologic uncertainties, and this should be included in the decision making on the planning of a retention area.

\section{References}

1. Bühlmann M. \& R.M. Boes (2014). Lateral flood discharge at rivers: Concepts and challenges. River Flow 2014 - Schleiss et al. (Eds), Taylor \& Francis, London, ISBN 978-1-138-02674-2. pp 1799-1806

2. CSO (2013). Technische evaluatie Rijnstrangen. Technical report. Document number: 13M2036 RAP, Version: 28-8-2013.

3. Dale, M., Wicks, J., Mylne, K., Pappenberger, F., Laeger, S. and S. Taylor (2014). Probabilistic flood forecasting and decision-making: an innovative riskbased approach. Natural hazards, 70(1): 159-172.

4. Deltaprogramma Rivieren (2014). Systeemwerking en bescherming langs de Maas, Onderzoek naar een robuust hoogwaterveiligheidssysteem. Editors: Lea Crijns, Hermjan Barneveld \& Silvia van 't Laar.

5. Gerretsen, J.H. (2009). Flood level prediction for regulated rain-fed rivers (Ph.D. Thesis). Enschede: University of Twente.

6. Hegnauer, M., Beersma, J. J., Van den Boogaard, H. F. P., Buishand, T. A. \& Passchier, R. H. (2014). Generator of Rainfall and Discharge Extremes (GRADE) for the Rhine and Meuse basins. Final report of GRADE 2.0. Deltares, Delft, The Netherlands.

7. Förster S., D. Kneis, M. Gocht and A. Bronstert (2005). Flood risk reduction by the use of retention areas at the Elbe River, International Journal of River Basin Management, 3(1): 21-29.

8. Klijn, F., van Buuren, M., and S. A. van Rooij (2004). Flood-risk management strategies for an uncertain future: living with Rhine River floods in the Netherlands?. Ambio, 33(3): 141-147.

9. Leander, R., Buishand, T.A., Aalders, P. \& Wit, M.J.M. de (2005). Estimation of extreme floods of the river Meuse using a stochastic weather generator and a rainfall-runoff model. Hydrological Sciences Journal, 50(6): 1089-1103.

10. Lörinc F. (2010). Reviewing the Tiszaroff flood retention reservoir - Lessons learnt from operating the Tiszaroff flood retention reservoir. Presentation Kisköre, 9 September, 2010

11. MRC (2011). The Mississippi River \& Tributaries Project: 2011 Flood Report.

12. Patzke, S. (2011). Verslag hoogwaters Maas november 2010 en Rijn en Maas januari 2011. Deltares report 1205043-000-ZWS-0012.

13. Plonka B., en A. Meuser (2013). Steuerung der Rückhaltungen Wörth/Jockgrim, Mechtersheim, Flotzgrün und Kollerinsel - Dokumentation und Berechnungsergebnisse. Landesamt für Umwelt, Wasserwirtschaft und Gewerbeaufsicht RheinlandPfalz. Mainz, Dezember 2013.

14. Pol, J. C., Barneveld, H. J., Morales Napoles, O., \& Schielen, R. M. J. (2015). Evaluation of design hydrograph methods and probabilistic methods for estimating design water levels on the river Meuse. $E$ proceedings of the 36th IAHR World Congress, The Hague, the Netherlands, 28 June-3 July 2015.

15. Rijkswaterstaat, (2012) WAQUA/TRIWAQ -twoand three-dimensional shallow water flow model. Technical documentation SIMONA report number 99-01.

16. Rijkswaterstaat (2018). https://waterberichtgeving.rws.nl/water-enweer/verwachtingenwater/rivieren/rijn/berichtgeving/archief/januari2018-deel-2 . Retrieved on December 14th, 2020.

17. Stijnen, J. (2007). Bergen met onzekerheden. Stromingen, 13(2): 11-22.

18. Verkade, J. S., Brown, J. D., Davids, F., Reggiani, P., and A. H. Weerts (2017). Estimating predictive 
FLOODrisk 2020 - $4^{\text {th }}$ European Conference on Flood Risk Management

hydrological uncertainty by dressing deterministic and ensemble forecasts; a comparison, with application to Meuse and Rhine. Journal of Hydrology, 555: 257-277. 